\title{
Utilização do Arduino como Ferramenta de Divulgação da Área Nuclear
}

\author{
Hudson Henrique da Silva ${ }^{1}$, Samira Santos da Silva ${ }^{2}$ \\ Departamento de Engenharia da Computação \\ Universidade do Estado de Minas Gerais (UEMG) \\ Divinópolis, Brasil \\ ${ }^{1}$ hudsonhenriquee@gmail.com, ${ }^{2}$ samirapgti@gmail.com
}

\author{
Sincler Peixoto de Meireles ${ }^{3}$ \\ Departamento de Ciências Exatas \\ Universidade do Estado de Minas Gerais (UEMG) \\ Divinópolis, Brasil \\ ${ }^{3}$ professorsincler@gmail.com
}

\begin{abstract}
O modelo tradicional de ensinoaprendizagem tem sido utilizado por muitos anos e consiste em aulas teóricas onde o professor é o sujeito ativo que transmite conhecimento aos alunos, denominados sujeitos passivos. Dessa forma, esse modelo está bastante centrado no professor. Entretanto, ele não se adequa a conteúdos que possuem natureza prática. Sendo assim, abordagens mais recentes de ensino propõem a utilização do acoplamento de diversos equipamentos eletrônicos com o propósito da construção de simuladores de ambientes da vida real a fim de tornar o aprendizado uma tarefa mais prazerosa e engajadora. Este trabalho possui como objetivo a construção de um simulador do reator nuclear de pesquisa TRIGA IPR-R1, localizado no Centro de Desenvolvimento de Tecnologia Nuclear (CDTN) em Belo Horizonte, Brasil, utilizando como ferramenta a plataforma de hardware livre Arduino. Através do simulador proposto, o usuário será capaz de perceber o quão simples e fácil é o processo de operação de um reator nuclear, tornando a aquisição de conhecimento sobre esta área uma tarefa mais interativa e prazerosa.
\end{abstract}

Keywords-Simulador; Reator Nuclear; Arduino;

\section{INTRODUCTION}

A aprendizagem pode ser compreendida como o processo de aquisição do conhecimento. Diversos trabalhos e pesquisas vêm sendo realizados a fim de encontrar estratégias de ensino que permitam otimizar o processo de aprendizagem, de forma que o aprendiz absorva o máximo de informações possíveis. A educação não-formal consiste em buscar o aprendizado que tem-se no ambiente escolar fora deste ambiente, como em museus, feiras de ciências, oficinas e etc, com o intuito de trazer ao visitante um conhecimento mais palpável, que por muitas das vezes não pode ser obtido através do ensino formal, até mesmo por muitas vezes ser aplicado a cenários que não são acessíveis a pessoas leigas, devido por exemplo a riscos [1].

Os museus interativos têm muita relação com as métricas pedagógicas, podendo ser trabalhadas diversas estratégias para se ter um envolvimento intelectual dos usuários, buscando sempre maximizar o aprendizado do visitante. De acordo com [2], o objetivo do museu interativo é "dar às pessoas uma experiência viva e colocar o público em contato com as tecnologias atuais". Entretanto, o museu interativo pode fazer mais que isso quando compreendido como espaço de divulgação científica e transmissão de conhecimento através de métodos não tradicionais.

Um dos principais recursos de museus interativos são os simuladores. Eles permitem com que o usuário tenha uma experiência mais realística do que ele representa sem necessariamente ter que se deslocar a ambientes que são de difícil acesso ou até mesmo manipular máquinas de grande tamanho e complexidade. Simuladores são úteis não somente na divulgação de conhecimento em museus interativos, mas também no processo de ensinoaprendizagem em sala de aula a fim de tornar o aprendizado uma tarefa mais prazerosa e engajadora.

Diversos tipos de equipamentos eletrônicos, incluindo hardwares livres, têm sido acoplados com o propósito da construção de simuladores de ambientes da vida real a fim de proporcionar uma sensação mais palpável e agradável a pessoas que antes consideravam a assimilação de conhecimento científico uma tarefa enfadonha e custosa. Consequentemente, a prática e utilização desses recursos no processo de aprendizagem acaba promovendo a aproximação entre a comunidade e a área científica.

Sendo assim, este trabalho possui como objetivo a utilização da plataforma de hardware livre Arduino na construção de um simulador do reator nuclear de pesquisa TRIGA IPR-R1 localizado no Centro de Desenvolvimento de Tecnologia Nuclear (CDTN) em Belo Horizonte, Brasil. Atualmente, este reator é utilizado em pesquisas e estudos científicos ligados principalmente à irradiação de amostras para análise por ativação neutrônica. Através do simulador proposto, o usuário será capaz de perceber o quão simples e fácil é o processo de operação de um reator nuclear, sem a necessidade de acessar a sua versão real que se encontra em uma sala com acesso restrito. No simulador, o usuário poderá ligar o reator, controlar sua operação, podendo aumentar ou diminuir a carga de trabalho, e também simular um desligamento de emergência, onde são interrompidas instantaneamente as fissões que ocorrem no núcleo do reator. 


\section{Trabalhos Relacionados}

Inúmeros trabalhos vem sendo propostos com o objetivo de utilizar simuladores para o ensino e aprendizagem de diferentes conteúdos. Estes trabalhos ressaltam a importância que o aprendizado interativo dispõe principalmente quando implementados na transmissão de conhecimentos de difícil assimilação.

No trabalho de [3], foi elaborado um material didático para o ensino de Óptica, área da física que estuda as leis associadas a radiações luminosas e fenômenos da visão. O material elaborado foi dirigido a professores e alunos do ensino médio, onde foram aplicadas algumas técnicas de aprendizagem recentes e tecnologias da informática que tornam o processo mais interessante aos olhos dos usuários. O trabalho foi desenvolvido em HTML, onde foram incluídos simuladores interativos, imagens estáticas e animações. Com isso, foi elaborado um CD-ROM com o material interativo. De acordo com $95 \%$ dos alunos entrevistados, o material resultou em maior estímulo e interesse pelas aulas de física.

O trabalho de [4] traz a proposta da elaboração de um software simulador, denominado SimDeCS, que proporciona aos seus usuários a oportunidade de um aprendizado interativo. Ele traz a oportunidade do usuário (alunos de medicina e áreas relacionadas) simular procedimentos reais na área da saúde. A proposta desse simulador seria trazer casos clínicos complexos, onde o usuário poderia testar seus conhecimentos e serem avaliados no final, possibilitando a identificação de seus acertos e falhas. Outro objetivo desse simulador seria a possibilidade da redução do aprendizado apenas teórico, aproximando-se mais do aprendizado prático.

Em um outro trabalho, desenvolvido por [5], foi realizado um estudo da utilização de computadores e simuladores interativos para auxílio no aprendizado e compreensão de alguns fenômenos físicos na área da física moderna e contemporânea. A análise foi feita a partir das perspectivas sócio-interativas de Vygotsky, que em sua teoria propõe que é na interação entre pessoas que se constrói o conhecimento. Sendo assim, a proposta da utilização do computador e de simuladores interativos viria para viabilizar e potencializar a interação entre estudantes e professores. Em seu trabalho, foram abordados três temas diferentes relacionados a FMC (Física Moderna e Contemporânea): espectroscopia, radioatividade e física nuclear. $\mathrm{Na}$ abordagem de todos os temas, foram utilizados simuladores virtuais diferentes desenvolvidos pelo grupo PhET (Projeto de Simulações Interativas da Universidade de Colorado Boulder).

Por fim, o trabalho de [6] desenvolve um estudo sobre a utilização de um simulador em um espaço de aprendizagem com o objetivo de análise sobre a sua influência no aprendizado do aluno em temas da área de Ciência e Tecnologia, relacionados a processos científicos. Além disso, estuda a importância da utilização de ferramentas digitais de aprendizagem (simuladores e outras ferramentas de apoio), e da metodologia de ensino por investigação em casos envolvendo ferramentas digitais de aprendizagem. Esses estudos de casos seguiram uma metodologia de caráter qualitativo com alunos de duas turmas do $8^{\circ}$ ano escolar da Escola Básica de Santa Catarina da Serra.

Muitos simuladores vêm sendo propostos na literatura. Entretanto, nenhum deles consiste em um simulador físico para o reator nuclear TRIGA IPR-R1, ou seja, nenhum permite o contato real e palpável com um reator deste tipo. Além disso, os poucos simuladores físicos de reatores que existem possuem propósito de treinamento e não de divulgação científica. Por isso, faz-se necessária a elaboração de abordagens neste sentido, principalmente, pelo fato de que sobre a área nuclear, a sociedade no geral possui pouco conhecimento e o pouco que sabem é sobre aspectos negativos, relacionados principalmente a acidentes, bombas ou até mesmo aos efeitos nocivos da radiação.

\section{Metodologia}

Reatores do tipo TRIGA são integrantes de uma classe de reatores de pequeno porte com o principal objetivo de pesquisa e formação de pessoal. O principal diferencial deste reator comparado aos demais é que ele não possui o risco de fusão do núcleo devido a excesso de temperatura [7]. Neste caso, o próprio elemento combustível atua como um regulador automático da sua potência. A Figura 1 consiste em um recorte lateral do reator TRIGA IPR-R1, onde é possível notar os elementos combustíveis, as guias das barras de controle - responsáveis por controlar as fissões no reator, o tubo central (TC) que é utilizado para que se possa levar materiais ao centro do núcleo a fim de torná-los expostos à radiação para análises em pesquisas, as placas inferiores e superiores e os refletores de grafita [7].

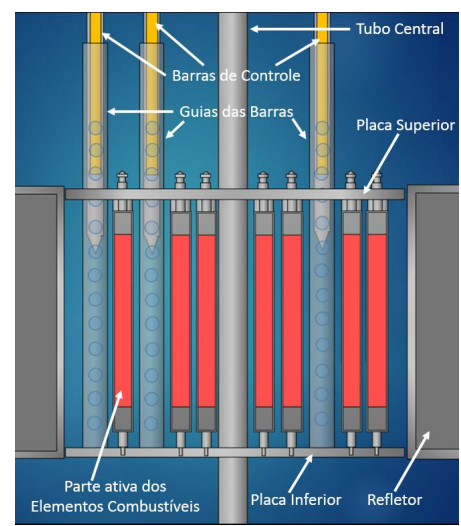

Figura 1: Núcleo do Reator TRIGA IPR-R1 [7]. 


\section{A. Definição dos Recursos Físicos}

Inicialmente, foi realizado um estudo sobre a viabilidade da construção do simulador do reator. Nesta etapa, foram definidos tamanho e escala das estruturas do simulador do reator para que, a partir disso, os componentes eletrônicos pudessem ser dimensionados com precisão. As placas superior e inferior do reator serão constituídas de madeirites de no mínimo $60 \mathrm{~cm}$ de diâmetro, a fim de suportar os demais componentes. O Elemento Combustível será constituído por cabos de madeira. Já para a construção do Tubo Central, definiuse que será utilizado um cano de $50 \mathrm{~mm}$ de diâmetro. Por fim, as Barras de Controle, para que sejam leves e assim o motor consiga tracioná-las sem dificuldade, serão construídas com papel cartolina.

\section{B. Definição dos Componentes Eletrônicos}

O principal componente a ser utilizado na prototipação do reator é o Arduino. Segundo [8], o Arduino é o que chamamos de plataforma de computação física ou embarcada. Sua utilização permite a interação com o ambiente através de hardware ou software. Este dispositivo pode ser programado para análise e tomada de decisões em entradas ou saídas que conectam a placa a componentes externos. A popularidade e facilidade em se trabalhar com esta placa é principalmente devido à facilidade de manuseio, montagem e manipulação da programação associados a ela. Outra vantagem dessa tecnologia é que a comunidade do Arduino é bastante colaborativa, resultando na disponibilização de diversos projetos e códigos prontos em fóruns, além de auxiliarem uns aos outros. A Figura 2 ilustra esta plataforma de hardware livre.

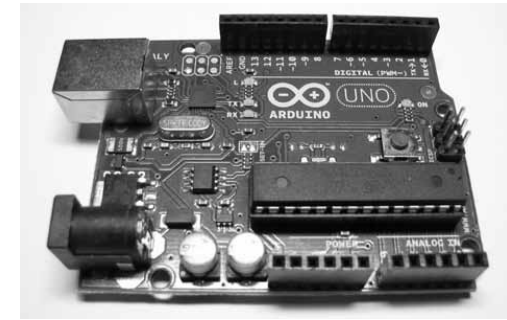

Figura 2: Exemplo da Plataforma Arduino Uno[8].

Além do Arduino, serão utilizados três motores do tipo G12-N20 Geared Mini DC Motor, cuja rotação pode ser invertida ao mudar o sentido da corrente que passa no mesmo, a fim de movimentar cada uma das Barras de Controle. Devido ao fato de que a quantidade de portas disponíveis na placa do Arduino não seria suficiente para suprir todas as conexões necessárias, surge a necessidade de utilização de um CI (Circuito Integrado) para expansão da quantidade de portas de saída disponíveis, o 74HC595. Outro circuito necessário é o CI L293D, com a função de facilitar a inversão de rotação dos motores. Serão necessários dois CIs deste tipo, visto que cada um deles tem a capacidade de gerenciar dois motores.

Serão utilizados também alguns componentes complementares, como uma fonte de 12VDC externa para alimentação dos motores, visto que o Arduino não consegue por si só fornecer essa energia. Será utilizado também uma Protoboard, para a conexão entre os componentes. Além disso, será utilizado um capacitor que fará a estabilização da energia de um dos CIs. E, por fim, alguns botões acompanhados de resistências, que serão utilizados para a interação do usuário com o simulador, através dos quais o mesmo poderá descer ou subir as barras de controle, subir todas as barras caso o reator tenha sido desligado e também um botão de emergência para descer rapidamente as barras, simulando assim um desligamento emergencial de um reator nuclear.

\section{Construção do Simulador}

A construção do circuito elétrico será realizada inicialmente utilizando a Protoboard, que é uma placa de ensaios que permite a montagens de circuitos elétricos experimentais, a fim de validar inicialmente que todas as funcionalidades desejadas no simulador sejam capazes de serem implementadas utilizando os componentes descritos na seção anterior.

Em seguida, é necessário realizar a programação da placa Arduino, que deve ser feita utilizando uma IDE própria. Ao término da programação, serão confeccionadas as partes físicas que irão compor o simulador, o que permitirá com que o usuário possa interagir e ver o equipamento se movimentando. A Figura 3 exibe o projeto do protótipo já montado em uma Protoboard.

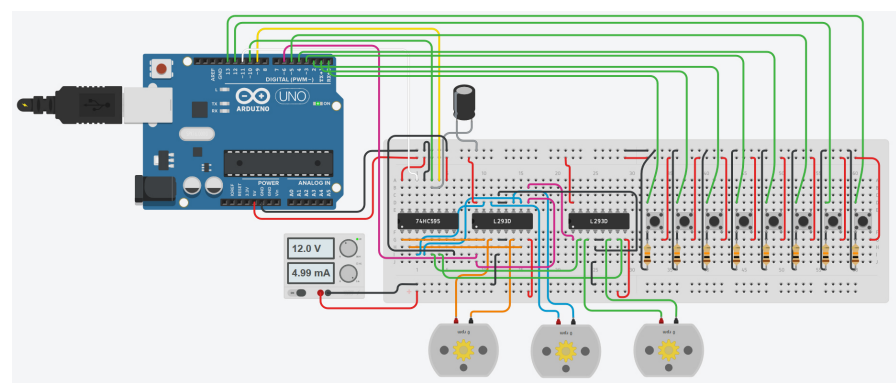

Figura 3: Protótipo do Circuito elétrico na Protoboard.

\section{Operação do Simulador}

Ao dar inicio à operação do simulador, o usuário inicialmente deve ligar o gerador. Após isso, é possível decidir descer quantas barras de controle quiser ou simplesmente desligar completamente o reator. É válido ressaltar que, para desligar o reator, é necessário que as três barras de controle estejam totalmente abaixadas. 
Portanto, mesmo que o usuário não pressione o botão para desligar o reator, se o mesmo descer as três barras, o reator desligará da mesma maneira.

\section{Resultados Preliminares}

A fim de avaliar a necessidade do simulador do Reator Triga IPR-R1 como ferramenta de divulgação científica da área nuclear, foram aplicados questionários a 70 pessoas de diferentes áreas, sendo a maior parte da área de Tecnologia da Informação e nenhuma delas da área Nuclear. Na primeira questão, decidiu-se por avaliar o quanto estas pessoas acreditam que operar um reator nuclear seja difícil para um profissional treinado. A Figura 4 exibe os resultados da pesquisa.

Para um profissional treinado, qual seria a dificuldade na operação de um reator nuclear?

70 responses

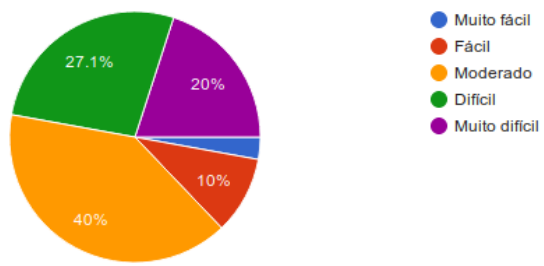

Figura 4: Resultado da Primeira Pergunta.

Em seguida, desejou-se avaliar o quanto estas pessoas sabem sobre as utilidades de um reator nuclear. A Figura 5 exibe os resultados da pesquisa.

De acordo com seus conhecimentos, quais são as utilidades de um reator nuclear?

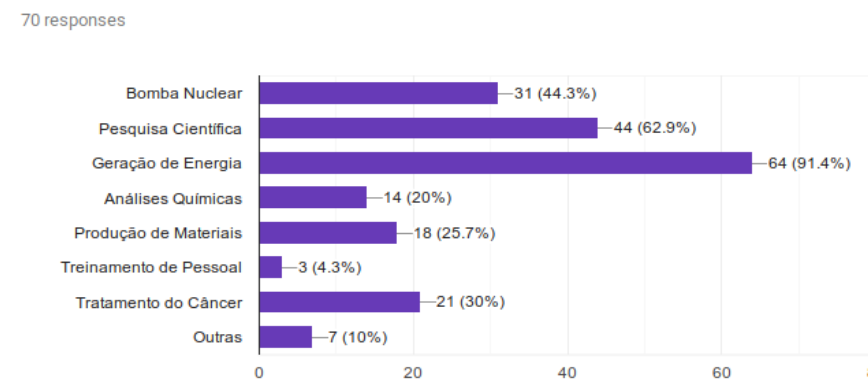

Figura 5: Resultado da Segunda Pergunta.

Por fim, as duas últimas perguntas questionavam se o indivíduo sabia o que era um reator de pesquisa e se gostaria de um dia aprender sobre e operar um reator deste tipo. O resultado mostrou que $88.6 \%$ dos entrevistados não sabe o que é um reator de pesquisa e $74.3 \%$ gostaria de aprender sobre e operar um reator deste tipo.

Analisando os resultados da Figura 4, podemos perceber que poucas pessoas consideram que operar um reator de pesquisa seja uma tarefa fácil ou muito fácil para um profissional treinado, o que demonstra total falta de conhecimento por parte dos entrevistados em relação à operação de um reator. Já nos resultados exibidos na Figura 5, podemos perceber que importantes utilidades do reator como Tratamento de Câncer e Análises Químicas praticamente não foram citados. Por fim, as respostas das duas últimas questões demonstram que os entrevistados não tinham conhecimento sobre reator de pesquisa e que achariam interessante ter a oportunidade de operá-lo, o que faz com que este trabalho seja de bastante significado.

\section{Próximos Passos}

A construção do simulador do reator nuclear IPR-R1 proposta neste trabalho possui como foco despertar em seus usuários a curiosidade e a capacidade investigativa necessárias para a compreensão de conceitos da área nuclear. As próximas atividades a serem desenvolvidas para a construção do simulador são respectivamente: validação do protótipo virtual, programação da placa Arduino, dimensionamento e confecção das peças para montagem do simulador, construção e validação do simulador.

\section{REFERÊNCIAS}

[1] V. Vieira, M. L. Bianconi, and M. Dias, "Espaços nãoformais de ensino e o currículo de ciências," Ciência e Cultura, vol. 57, no. 4, pp. 21-23, 2005.

[2] T. C. D. SANTOS, "Museu interativo de vídeo jogos," Trabalho de Conclusão de Curso (Graduação em Design de Ambientes)-Universidade do Estado de Minas Gerais, 2012 .

[3] V. Heckler, M. d. F. O. Saraiva, and K. d. S. Oliveira Filho, "Uso de simuladores, imagens e animações como ferramentas auxiliares no ensino/aprendizagem de óptica," 2007.

[4] P. R. M. Barros, S. C. Cazella, M. Bez, C. D. Flores, A. Dahmer, J. B. Mossmann, J. M. Fonseca, and V. Maroni, "Um simulador de casos clínicos complexos no processo de aprendizagem em saúde," RENOTE, vol. 10, no. 1,2012 .

[5] A. A. Soares, L. E. Moraes, and F. G. Oliveira, "Ensino de matéria e radiação no ensino médio com o auxílio de simuladores interativos," Caderno Brasileiro de Ensino de Física, vol. 32, no. 3, pp. 915-933, 2015.

[6] R. S. R. d. Santos, "O simulador photolab num espaço de aprendizagem por investigação no desenvolvimento de competências do processo científico," Ph.D. dissertation, Escola Superior de Educação e Ciências Sociais, 2018.

[7] S. P. de Meireles, "Modelagem e cálculo de queima do reator triga ipr-r1 utilizando os códigos mcnpx e serpent," 2018.

[8] M. McRoberts, Arduino Básico-2 ${ }^{a}$ edição: Tudo sobre o popular microcontrolador Arduino. Novatec Editora, 2015. 